\title{
Originals
}

\section{Prevalence of diabetes mellitus in elderly men aged 65 to 84 years in eastern and western Finland}

\author{
J. Tuomilehto, ${ }^{1}$ A. Nissinen ${ }^{1}$, S.-L. Kivelä2 ${ }^{2}$ J.Pekkanen ${ }^{1}$, E. Kaarsalo ${ }^{3}$, E. Wolf ${ }^{1}$, A. Aro ${ }^{1}$, S. Punsar $^{4}$ \\ and M.J.Karvonen ${ }^{5}$ \\ ${ }^{3}$ Department of Epidemiology, National Public Health Institute, Helsinki, ${ }^{2}$ Department of Public Health, University of Tampere, Tampere, \\ ${ }^{3}$ Department of Medicine, Loimaa District Hospital, Loimaa, and ${ }^{4}$ Laakso Hospital, City of Helsinki, Helsinki, Finland; ${ }^{5}$ Pioppi, Italy
}

\begin{abstract}
Summary. We studied the prevalence of diabetes mellitus in men aged 65 to 84 years in Finland. The study sample consisted of 763 men, the survivors of the Finnish cohort of the "Seven Countries Study" first examined in 1959. The participation rate in the present survey was $94 \%$. Blood glucose, fasting and $2 \mathrm{~h}$ after a 75 -g oral glucose load, was determined from capillary blood. Current WHO criteria for diabetes mellitus were used. The mean fasting blood glucose level, adjusted for age and body mass index, was higher in east than west Finland. It rose with age in both areas. The prevalence of diabetes was $38 \%$ in the east and 36\% in west Finland. About one-third of the men had impaired glucose tolerance. In the age group 75
\end{abstract}

to 79 years, the prevalence of diabetes was $65 \%$ in the east and $50 \%$ in the west. No systematic variation in the prevalence of impaired glucose tolerance with age was found. The mean levels of body mass index decreased with age in the same way in men with diabetes, impaired glucose tolerance and normal glucose tolerance. Body mass index was not higher in men with diabetes or impaired glucose tolerance than in men with normal glucose tolerance.

Key words: Type 2 diabetes, diabetes prevalence, blood glucose, glucose tolerance, epidemiology.
The prevalence and incidence of diabetes mellitus vary considerably between population and between different age groups within populations [1,2]. Recent revisions in classification and diagnostic criteria for diabetes mellitus by the World Health Organization in 1980 [3] and 1985 [4] have reduced the methodological problems of diagnosis often found in earlier studies which have made direct comparisons between studies impossible [1, 2]. Diabetes is known to be prevalent in elderly, but until now only few epidemiological studies on diabetes in the elderly have reported their data according to WHO criteria.

It has been suggested that the prevalence of diabetes is about $17 \%$ in people older than 65 years in the United States $[5,6]$. The second National Health and Nutrition Examination Survey (Hanes II) in the USA found a prevalence of diabetes of $17 \%$ in Caucasoid persons and $25 \%$ in Black persons aged 65-74 in 1976-80 [7]. In Finland the prevalence of Type 1 (insulin-dependent) diabetes in children and adolescents is known to be the highest in the world $[8,9]$, and there is good evidence to suggest that Type 2 (non-insulin-dependent) diabetes is also at least as prevalent as in other developed countries $[10,11]$.

A cohort of men born in eastern and western Finland between 1900 and 1919 were examined first in 1959 in connection with the Seven Countries Study [12, 13]. A 25-year follow-up was accomplished in 1984. The present paper examines the prevalence of diabetes in the survivors of this well-defined cohort of elderly men.

\section{Subjects and methods}

\section{Subjects}

The survey was carried out from October to November 1984. The study sample consisted of 763 men, 334 from eastern and 414 from western Finland, of whom 716 participated in the present survey. The participation rates were $95 \%$ and $93 \%$ in eastern and western Finland respectively. The 763 men were the survivors of the 1711 men of the Finnish cohort of the Seven Countries Study $[11,12]$ first examined in 1959 and followed up for 25 years. The original cohort consisted of all men born 1900-19 from two geographically defined areas, one in eastern and one in western Finland. The procedures of the 1984 survey have been described elsewhere in more detail [14]. The population of the present study in 5-year age groups is shown in Table 1.

\section{Procedures}

All men were asked to fast at least $4 \mathrm{~h}$ before their appointment at the clinic. The examinations took place between 08.00 and 16.30 hours. Everyone received a letter of invitation which included instructions for fasting and stated the exact time reserved for the clinical examination. At the clinic, capillary blood samples were obtained before and $2 \mathrm{~h}$ after a $75-\mathrm{g}$ oral glucose load. All blood glucose measurements were determined from capillary blood using a refractometric method, i.e. by reading Dextrostix sticks in a Glucometer refractometer (Miles Laboratories, Ames Division, Elkhart, Ind, USA) [15]. Excellent correlation and satisfactory replication has been obtained with this method when used in a careful way in comparison to Auto Analyzer or the Hexokinase method $[15,16]$. The correct use in our study was assured by adequate training of one laboratory technician who carried out practically all the measurements. During the training period, three control sera with low, intermediate and high glucose concentrations were used in mixed order with other sera. The training was considered adequate when all determinations within one day with the control sera had a precision of at least $95 \%$. During the field survey, the equipment was calibrated daily using the control sera with low 
Table 1. Values (mean $\pm \mathrm{SD}$ ) of fasting capillary blood glucose and blood glucose measured $2 \mathrm{~h}$ after a glucose load of $75 \mathrm{~g}$ by age group in men aged 65 to 84 years in eastern and western Finland

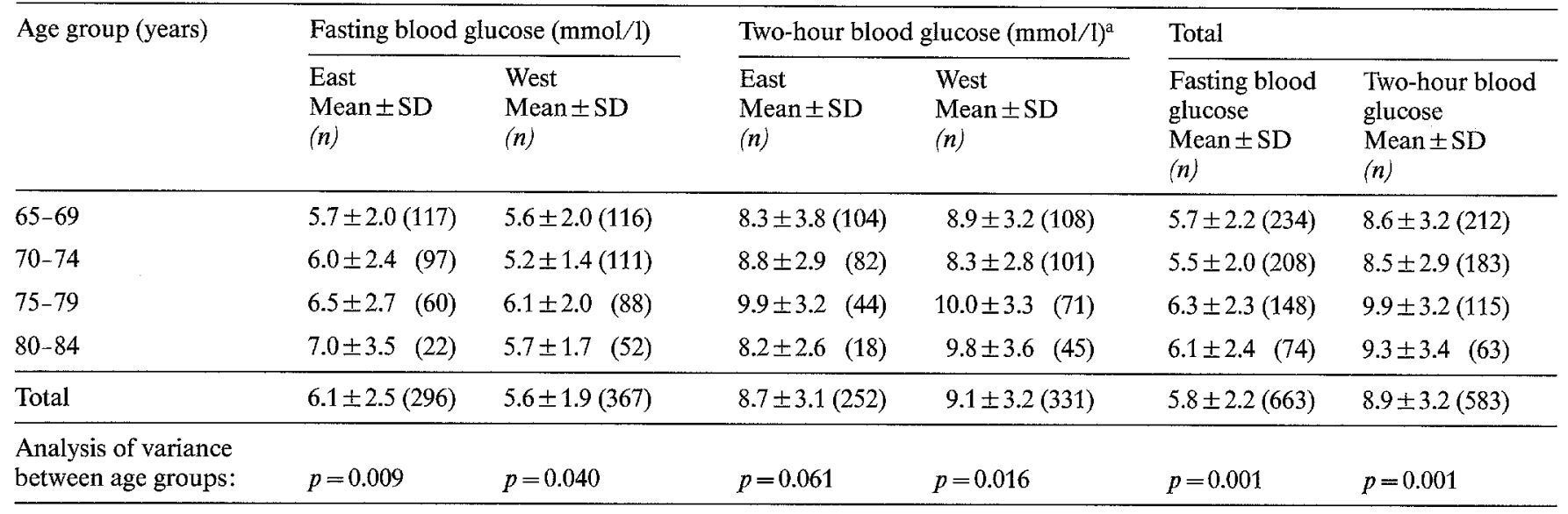

a People known to have diabetes or fasting blood glucose $10.0 \mathrm{mmol} / 1$ or more were not included in the oral glucose tolerance test

and high concentrations. Every second day the precision of the measurement technique was validated against the intermediate control sera. In the case of measurement error more than $5 \%$, specific procedures were included in the study protocol. However, these procedures were never needed, since the error in the quality assurance test never exceeded the $5 \%$ level.

Men (62 in eastern Finland and 56 western Finland) who were treated with insulin or oral hypoglycaemic agents, or whose fasting blood glucose was over $10 \mathrm{mmol} / 1$, were excluded from the glucose tolerance test. All men were classified hierarchically according to the current WHO criteria for diabetes mellitus [4]: (1) Diabetes mellitus 2-h postchallenge capillary blood glucose level $>11.0 \mathrm{mmol} / 1$ or hypoglycaemic drug treatment; (2) Impaired glucose tolerance (IGT) 2-h blood glucose $8.0-11.1 \mathrm{mmol} / 1$; (3) Normal - 2-h blood glucose $>8.0 \mathrm{mmol} / 1$.

Fifty-three men could not be classified according to these criteria because 22 participated only in the assessment of blood glucose, and 31 had no glucose determinations done at all. Three of these 53 men reported that they had been told that they had diabetes but none of them had ever been treated with hypoglycaemic drugs.

\section{Statistical analysis}

The statistical evaluation of differences in the mean values between the strata by age group and diabetes status was carried out by the analysis of variance using the SAS general linear models procedure.

\section{Results}

The mean fasting capillary blood glucose level was significantly higher in eastern than in western Finland $(p<0.001)$ (Table 1). In the east the mean fasting blood glucose level rose with age $(\mathrm{p}=0.009)$. In the west, such an increasing trend with age was not seen, and the highest mean level was found in the age group 75-79 years. In each 5-year age group the mean fasting blood glucose was higher in the east than the west.

The mean 2-h blood glucose level was highest in men aged 75-79 years. The fall in the oldest age group of 80-84 years was especially marked in the east. The mean 2 -h blood glucose level was slightly higher in the west than in the east, except in men aged 70-74 years, but the differences between areas were nonsignificant.

Table 2 gives the prevalences of diabetes and IGT for men in the east and west of Finland by 5-year age
Table 2. Prevalence of diabetes mellitus and impaired glucose tolerance (IGT) by area and age group

\begin{tabular}{|c|c|c|c|c|c|c|c|c|c|c|c|}
\hline \multirow{3}{*}{\multicolumn{2}{|c|}{$\begin{array}{l}\text { Age group } \\
\text { (years) }\end{array}$}} & \multicolumn{2}{|c|}{ Normal } & \multicolumn{2}{|c|}{$\mathrm{IGT}$} & \multirow{2}{*}{\multicolumn{2}{|c|}{$\begin{array}{l}\text { Diabetes } \\
\text { previously } \\
\text { unknown }\end{array}$}} & \multirow{2}{*}{\multicolumn{2}{|c|}{$\begin{array}{l}\text { Diabetes } \\
\text { previously } \\
\text { known }\end{array}$}} & \multicolumn{2}{|c|}{ Total } \\
\hline & & \multirow[t]{2}{*}{$n$} & \multirow[t]{2}{*}{$\%$} & \multirow[t]{2}{*}{$n$} & \multirow[t]{2}{*}{$\%$} & & & & & \multirow[t]{2}{*}{$n$} & \multirow[t]{2}{*}{$\%$} \\
\hline & & & & & & $n$ & $\%$ & $n$ & $\%$ & & \\
\hline \multirow[t]{5}{*}{ East $^{\mathrm{a}}$} & $65-69$ & 56 & 46.7 & 37 & 30.8 & 17 & 14.7 & 10 & 8.3 & 120 & 100.0 \\
\hline & $70-74$ & 34 & 34.0 & 37 & 37.0 & 16 & 16.0 & 13 & 13.0 & 100 & 100.0 \\
\hline & $75-79$ & 20 & 30.3 & 16 & 24.2 & 16 & 24.2 & 14 & 21.2 & 66 & 100.0 \\
\hline & $80-84$ & 10 & 41.6 & 8 & 33.3 & 2 & 8.3 & 4 & 16.7 & 24 & 100.0 \\
\hline & total & 120 & 38.7 & 98 & 31.6 & 51 & 16.5 & 41 & 13.2 & 310 & 100.0 \\
\hline \multicolumn{2}{|c|}{ West $^{\mathrm{b}} 65-69$} & 45 & 38.8 & 38 & 32.8 & 28 & 24.1 & 5 & 4.3 & 116 & 100.0 \\
\hline & $70-74$ & 60 & 51.3 & 33 & 28.2 & 17 & 14.5 & 7 & 6.0 & 117 & 100.0 \\
\hline & $75-79$ & 24 & 26.1 & 29 & 31.5 & 24 & 26.1 & 15 & 16.3 & 92 & 100.0 \\
\hline & $80-84$ & 15 & 28.3 & 21 & 39.6 & 12 & 22.6 & 5 & 9.4 & 53 & 100.0 \\
\hline & Total & 144 & 38.1 & 121 & 32.0 & 81 & 21.4 & 32 & 8.5 & 378 & 100.0 \\
\hline
\end{tabular}

${ }^{a}$ Data missing in 25 men; ${ }^{b}$ data missing in 28 men

groups. Both in the east and in the west, $30 \%$ of men had diabetes and $32 \%$ had IGT. The prevalence of diabetes was particularly high in men aged $75-79$ years (45\% and $42 \%$ ). The lowest prevalence of diabetes was found in the youngest age group of $65-69$ years ( $23 \%$ in the east and $28 \%$ in the west).

The prevalence of IGT varied with age ranging from $24 \%$ to $40 \%$, but in the prevalence of IGT no systematic trend was found either with age or between areas.

Of the diabetic patients, $45 \%$ in the east but only $28 \%$ in the west were aware of their condition before the survey. The proportion of those unaware was especially high in the youngest age group of 65-69 years (62\% in the east and $85 \%$ in the west). Although the overall prevalence of diabetes was the same $(30 \%)$ for both areas, the prevalence of known diabetes was $13 \%$ in the east and $9 \%$ in the west, giving a false impression about a regional difference. This problem was especially pronounced in the age group 65-74 years, where the prevalence of known diabetes was $11 \%$ in the east and $5 \%$ in the west, but the actual prevalence was $24 \%$ for both areas.

The higher overall mean fasting blood glucose level in the east was mainly due to the difference in the blood glucose level in diabetic subjects. Men with IGT did not 
Table 3. Values (mean $\pm \mathrm{SD}$ ) of fasting blood glucose by area, age group and diabetes status

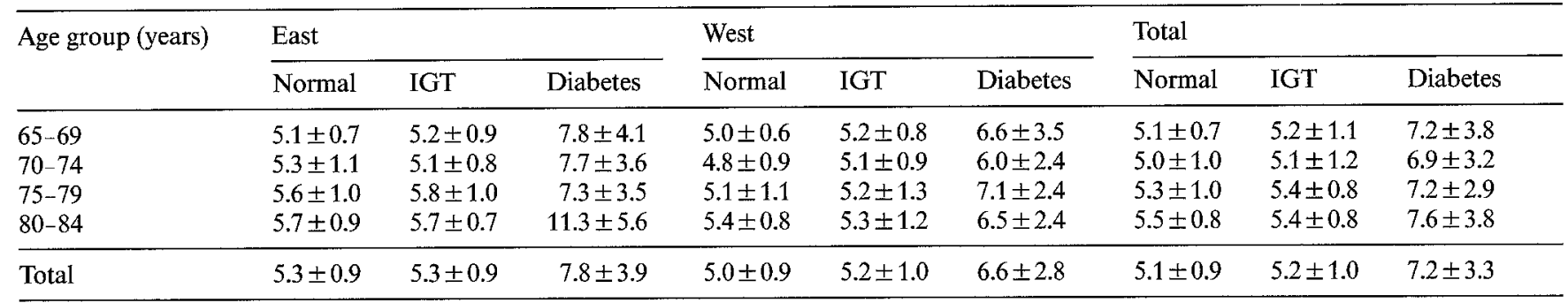

Analysis of variance: diabetes status, $p<0.001$; age group NS. Interaction: diabetes status, age group NS

Table 4. Values (mean \pm SD) of 2-h capillary blood glucose by area, age and diabetes status

\begin{tabular}{|c|c|c|c|c|c|c|c|c|c|}
\hline Age group (years) & \multicolumn{3}{|l|}{ East } & \multicolumn{3}{|l|}{ West } & \multicolumn{3}{|l|}{ Total } \\
\hline $70-74$ & $\begin{array}{c}5.8 \pm 1.3 \\
(30)\end{array}$ & $\begin{array}{l}9.2 \pm 0.9 \\
(37)\end{array}$ & $\begin{array}{c}13.1 \pm 1.6 \\
(17)\end{array}$ & $\begin{array}{c}6.2 \pm 1.2 \\
(52)\end{array}$ & $\begin{array}{c}9.2 \pm 0.8 \\
(33)\end{array}$ & $\begin{array}{l}12.9 \pm 1.9 \\
(18)\end{array}$ & $\begin{array}{l}6.0 \pm 1.2 \\
(82)\end{array}$ & $\begin{array}{c}9.2 \pm 0.9 \\
(70)\end{array}$ & $\begin{array}{c}13.0 \pm 1.8 \\
(35)\end{array}$ \\
\hline $80-84$ & $\begin{array}{c}6.1 \pm 1.4 \\
(9)\end{array}$ & $\begin{array}{c}9.6 \pm 1.1 \\
(8)\end{array}$ & $\begin{array}{l}14.5 \pm 0.0 \\
\text { (1) }\end{array}$ & $\begin{array}{c}5.9 \pm 1.2 \\
(12)\end{array}$ & $\begin{array}{c}9.6 \pm 0.9 \\
(21)\end{array}$ & $\begin{array}{c}14.0 \pm 2.9 \\
(12)\end{array}$ & $\begin{array}{c}5.9 \pm 1.2 \\
(21)\end{array}$ & $\begin{array}{l}9.6 \pm 1.0 \\
(29)\end{array}$ & $\begin{array}{c}14.1 \pm 2.8 \\
(13)\end{array}$ \\
\hline $\begin{array}{l}\text { Total } \\
n\end{array}$ & $\begin{array}{l}6.0 \pm 1.3 \\
(105)\end{array}$ & $\begin{array}{l}9.1 \pm 0.9 \\
(98)\end{array}$ & $\begin{array}{l}13.4 \pm 2.3 \\
(49)\end{array}$ & $\begin{array}{l}6.0 \pm 1.2 \\
(126)\end{array}$ & $\begin{array}{l}9.3 \pm 0.9 \\
(121)\end{array}$ & $\begin{array}{c}13.3 \pm 2.1 \\
(84)\end{array}$ & $\begin{array}{l}5.9 \pm 1.2 \\
(231)\end{array}$ & $\begin{array}{l}9.3 \pm 0.9 \\
(219)\end{array}$ & $\begin{array}{l}13.4 \pm 3.2 \\
(138)\end{array}$ \\
\hline
\end{tabular}

Analysis of variance: age group, $p=0.040$

Table 5. Values (mean $\pm \mathrm{SD}$ ) of body mass index $\left(\mathrm{kg} / \mathrm{m}^{2}\right)$ by area, age group and diabetes status

\begin{tabular}{llllllll}
\hline $\begin{array}{l}\text { Age group } \\
\text { (years) }\end{array}$ & \multicolumn{1}{l}{ East } & \multicolumn{5}{l}{ West } \\
\cline { 2 - 3 } & Normal & IGT & Diabetes & & Normal & IGT & Diabetes \\
\hline $65-69$ & $25.3 \pm 4.0$ & $25.9 \pm 3.7$ & $25.5 \pm 4.3$ & & $26.3 \pm 4.3$ & $26.3 \pm 3.9$ & $27.5 \pm 3.6$ \\
$70-74$ & $26.4 \pm 3.6$ & $26.0 \pm 4.7$ & $26.6 \pm 4.8$ & & $25.8 \pm 4.5$ & $27.0 \pm 4.3$ & $26.5 \pm 3.0$ \\
$75-79$ & $25.0 \pm 4.8$ & $25.3 \pm 3.6$ & $24.1 \pm 3.1$ & & $25.2 \pm 2.7$ & $25.1 \pm 3.5$ & $26.2 \pm 4.6$ \\
$80-84$ & $24.0 \pm 3.1$ & $22.8 \pm 3.7$ & $22.4 \pm 4.0$ & & $23.6 \pm 3.8$ & $25.1 \pm 4.6$ & $24.9 \pm 4.1$ \\
\hline Total & $25.3 \pm 4.0$ & $25.6 \pm 3.9$ & $25.2 \pm 4.2$ & & $25.6 \pm 4.2$ & $26.0 \pm 4.1$ & $26.4 \pm 4.0$ \\
\hline
\end{tabular}

Analysis of variance: diabetes status NS; age group $p<0.001$. Interaction: diabetes status, age group NS

have higher mean fasting blood glucose levels than men with normal glucose tolerance. The difference in fasting blood glucose level between the diabetic and non-diabetic men was larger. Diabetic patients in the age group $80-84$ years in the east had particularly high values.

The mean 2-h blood glucose values for men who were not previously known to have diabetes are shown in Table 4. Overall, the $2-\mathrm{h}$ glucose level varied only little, although significantly $(p=0.040)$, with age. The age-specific levels for the two areas were not different. In men with diabetes and IGT, it was the oldest age group which had the highest 2-h blood glucose level, whereas in men with normal glucose tolerance the highest mean level was found in the middle age groups.

The mean levels of body mass index (BMI) indicated that obesity was not prevalent in the study population (Table 5). The mean BMI in western Finland was slightly higher than that in eastern Finland in each category of diabetes status. Neither diabetic men nor men with IGT had a significantly higher BMI than those with normal glucose tolerance. In the east in each strata and in the west in men with IGT the highest mean BMI value was seen in the age group 70-74 years and, thereafter, it decreased with increasing age, as it did in the west in normal and diabetic men over the entire age range.

\section{Discussion}

The prevalence of diabetes mellitus in men aged 65 to 84 years was found to be extremely high. Using the new 1985 WHO criteria [4], about one-third of the elderly men studied had diabetes. The prevalence was approximately the same both in eastern and western Finland, and in our study was higher than in most other studies of elderly populations. Comparisons of diabetes prevalence between different populations have earlier been hampered by several methodological problems, but the recent criteria recommended by the WHO Expert Committee in 1980 [3] and revised in 1985 [4] will reduce this problem in the future.

The Pima Indians are known to have the highest prevalence of diabetes in the world [17, 18]. In male Pima Indians aged 65 to 74 years, this prevalence is about $40 \%$; in the age group 75 to 84 years, it is about $35 \%$, although the number of elderly Pima Indians is very small [18]. Thus, the prevalence of diabetes in elderly Finnish men was of the same order as that found in the Pima Indians. The diagnostic criteria for diabetes in the Pima 
Indian survey - clinical diagnosis of diabetes or a $2-\mathrm{h}$ post load plasma glucose of $200 \mathrm{mg} / \mathrm{dl}$ or known clinical diabetes - differed only slightly from that of our present study. The most striking difference between the Pima Indians and our study population is that the Pima Indians are extremely obese, whereas obesity was not common in the Finnish men studied.

The second National Health and Nutrition Examination Survey (Hanes II) in the USA carried out between 1976-1980 [7] used the criteria suggested by the National Diabetes Data Group in 1979 [19], which are essentially the same as the WHO criteria. Hanes II reported a prevalence of diabetes of $18 \%$ for Caucasoid and $27 \%$ for Black men aged 65 to 74 years. The prevalence in Finnish men in the same age group was similar to that in US Black men. In the recent diabetes survey in Malta, where Type 2 diabetes is known to be very common, the prevalence was $19 \%$ in men aged 65 to 74 years [20]. All other earlier prevalence studies in elderly Caucasoid populations, unfortunately using varying methods and criteria, reported less than 15\% diabetes for men aged 65 years or more [21-30]. Some of the surveys in the male populations of the Pacific Islands showed a very high prevalence in middle-aged men [31], but usually a lower prevalence of diabetes in the elderly than that in Finnish men. Only the Republic of Nauru, which has the highest prevalence of diabetes in the $\mathrm{Pa}$ cific Basin - about 35\% in the population over 15 years of age [32] - may have a still higher frequency of diabetes, although the number of Nauruan people over 65 years of age is small.

The peak prevalence in our present study was in the age group 75 to 79 years, in which half of the men had diabetes. The prevalence started to decline thereafter. For the age group 75 to 84 years the prevalence in our study material was higher than reported in any other population of this age. In a recent Swedish study in the small community of Ystad, the peak prevalence of diabetes was found in the age group 80 to 84 years [36], but it was as low as $10 \%$.

In a survey carried out in Finland among the citizens of Tampere aged 85 years or more, a diabetes prevalence of $16 \%$ for men was reported [45]. This prevalence estimate fits rather well with our findings, although in our present study men over 85 years of age were not included. There are two other recent attempts to estimate prevalence of diabetes where elderly populations were included $[10,11]$. Unfortunately, neither of these studies have used the WHO criteria for diabetes but are based on known or reported diabetes. In 1979-80, according to Reunanen [10], the prevalence was $7 \%$ in men aged 60 to 74 years and about $10 \%$ for the men over 70 years. The study provided some suggestive evidence that the prevalence of diabetes in the elderly has increased (almost doubled) during the 1970s. Much of this might be because of better diagnostic procedures and due to the introduction of free-ofcharge drug treatment for diabetes in Finland in 1970.
Another study reviewed all medical records of an area in eastern Finland [11]; the prevalence of previously known diabetes in men was found to increase up till the age of 65 years, but the peak prevalence reported was only about $5 \%$. In our study the prevalence of known diabetes was $23 \%$ and the prevalence of treated diabetes $11 \%$. These differences stress the importance of standardized methodology and criteria for comparisons attempted between studies. Our results showed very clearly the possibility of a bias if only self-reported cases or treated patients are considered diabetic. The east-west difference (13\% vs. $9 \%$ ) completely disappeared when the results of the oral glucose tolerance test were taken into account.

Our study population was initially part of the wellknown epidemiological study of cardiovascular diseases, the Seven Countries Study. The incidence of and mortality from coronary heart disease in men originally belonging to this particular cohort was found to be the highest in the world $[12,13]$. Unfortunately, standardized assessment of diabetes mellitus was not done in earlier examinations of this cohort. More than half of the men who originally belonged to this cohort had died by $1984,41 \%$ from coronary heart disease.

Jarrett [34] recently reviewed the literature, finding evidence against a correlation between the duration of Type 2 diabetes mellitus and the risk of coronary heart disease. He proposed that Type 2 diabetes is associated with but not causally related to coronary heart disease. Our present study indirectly supports Jarrett's hypothesis, as such a high frequency of diabetes among the long-term survivors of this cohort of men would be otherwise unlikely.

The association of diabetes and aging may be secondary to decreased glucose tolerance $[1,2,35]$, but our knowledge of factors associated with diabetes in elderly is rather limited. The decline in glucose tolerance starts in the third to fourth decade, and it is believed that it is progressive throughout the entire life span [36-38]. Several factors, including increase of fat in proportion to muscle tissue, i.e. decreased lean body mass $[26,36$, 37], and decreased physical activity [37-39] appear to contribute to this decrease in glucose tolerance. It seems likely that the aging process has an independent effect of tissue sensitivity to insulin [36, 37, 40, 41]. In our cross-sectional study we did not find any correlation between body mass index and glucose intolerance.

Although our study confirmed the increased occurence of overt diabetes with advancing age, we did not find a linear trend of increasing fasting or 2-h blood glucose with age in men with IGT or normal glucose tolerance. Furthermore, the inter-individual variation in both fasting and 2-h blood glucose did not increase with age at all. Thus, the major contribution to the age-related rise in blood glucose concentration in our population was the increasing number of diabetic men with age. Our results are, in this respect, in full agreement with those of Zimmet et a1. [42], who found in Polyne- 
sian men and women only little change in both fasting and postload glucose concentrations with age except for the 90 th percentile.

\section{References}

1. West KM (1978) Epidemiology of diabetes and its vascular lesions. Elsevier, North-Holland, New York

2. Davidson MD (1979) The effect of aging on carbohydrate metabolism. A review of the English literature and a practical approach to the diagnosis of diabetes mellitus in the elderly. Metabolism 28: $688-705$

3. WHO Expert Committee on Diabetes Mellitus Second report (1980) World Health Organisation Tech Rep Ser 646 WHO Geneva

4. WHO Study Group on Diabetes Mellitus (1985) World Health Organization Tech Rep Ser 727, WHO, Geneva

5. Bennett PH (1984) Diabetes in the elderly: diagnosis and epidemiology. Geriatrics 39 (No 5): $37-41$

6. Williams T (1978) Diabetes mellitus in the aged. Greenblatt, $R$, (ed) In: Geriatric endocrinology. Raven, New York

7. Harris M (1985) Prevalence of noninsulin-dependent diabetes and impaired glucose toletance. In: National Diabetes Data Group. Diabetes in America, NIH Publication No. 85-1468, US Government Printing Office, pp VI-1-VI-31

8. Reunanen A, Åkerblom HK, Käär M-L (1982) Prevalence and ten year (1970-1979) incidence of insulin-dependent diabetes mellitus in children and adolescents in Finland. Acta Paediatr Scand 71: 893-899

9. Åkerblom HK, Reunanen A (1985) The epidemiology of insulindependent diabetes mellitus (IDDM) in Northern Europe, with particular emphasis on the country with the highest incidence and prevalence, Finland. Diabetes Care 8 (Suppl 1): 1-16

10. Reunanen A (1984) Prevalence and incidence of type 2 diabetes in Finland. Acta Endocrinol 105 (Suppl 262): 31-35

11. Laakso M, Pyörälä K (1985) Age of onset and type of diabetes. Diabetes Care 8: 114-117

12. Karvonen M, Blomqvist G, Kallio V, Orma E, Punsar S, Rautaharju P, Takkunen J, Keys A (1967) Epidemiological studies related to coronary heart disease: characteristics of men aged 40-59 in seven countries C 4. Men in rural east and west Finland. Acta. Med Scand 460 (Suppl 169)

13. Keys A (1970) Coronary heart disease in seven countries. Monograph Nr. 29. American Heart Association, New York

14. Kivelä S-L, Nissinen A, Tuomilehto J, Pekkanen J, Punsar S, Lammi U-K, Puska P (1986) Prevalence of depressive and other symptoms in elderly Finnish men. Acta Physiatr Scand 73: 93-100

15. Jarrett RJ, Keen H, Hardwick C (1970) Instant blood sugar measurement using Dextrostix and a reflectance meter. Diabetes 19: 724

16. Stewart TC (1976) Evaluation of a reagent-strip method for glucose in whole blood, as compared with a Hexokinase method. Clin Chem 1: 74-78

17. Bennett PH, Burch TA, Miller M (1971) Diabetes mellitus in American (PIMA) Indians. Lancet 2: 125-128

18. Knowler WC, Bennet PH, Hamman RF, Miller M (1978) Diabetes incidence and prevalence in Pima Indians: a 19-fold greater incidence than in Rochester, Minnesota. Am J Epidemiol 108: 497-505

19. National Diabetes Data Group (1979) Classification of diabetes mellitus and other categories of glucose intolerance. Diabetes 38: 1039-1057

20. Katona G, Aganovic I, Vuksan V, Skrabalo Z, Hoet JJ, Grech A (1986) National Diabetes Programme in Malta. Diabetologia Croat XV-2: $47-70$

21. Damsgaard E (1984) Prevalence and incidence of type II diabetes in Denmark compared with other countries. Acta Endocrinol 105 (Suppl 262): 21-26
22. Welborn TA, Curnow DH, Wearne JT, Cullan KI, McCall MG, Stenhouse NS (1968) Diabetes detected by blood-sugar measurement after a glucose load: report from the Busselton Survey, 1966. Med J Australia 778-783

23. Haynes NS, Kjelsberg MO, Epstein FH, Francis T, Arbor A (1965) Carbohydrate tolerance and diabetes in a total community, Tecumseh, Michigan. Diabetes 14: 413-423

24. Falconer DS, Duncan LJP, Smith C (1971) A statistical and genetical study of diabetes. I. Prevalence and morbidity. Ann Hum Genet 34: 347-369

25. Palumbo PJ, Elveback IR, Chu C-P, Connolly DC, Kurland IT (1976) Diabetes mellitus: incidence, prevalence, survivorship and cause of death in Rochester, Minnesota 1945-1970. Diabetes 25: 566-573

26. Barret-Connor E (1980) The prevalence of diabetes mellitus in an adult community as determined by history or fasting hyperglycemia. Am J Epidemiol 111: 705-712

27. Agner E, Thorsteinsson B, Eriksen M (1982) Impaired glucose tolerance and diabetes mellitus in elderly subjects. Diabetes Care 5: 600-604

28. Kannel WB, Daniel L, McGee L (1979) Diabetes and cardiovascular risk factors: the Framingham Study. Circulation 59: 8-13

29. Jarrett J, McCartney P, Keen H (1982) The Bedford survey: Tenyear mortality rates in newly diagnosed diabetics, borderline diabetics, and normoglycaemic controls and risk incides for coronary heart disease in borderline diabetics. Diabetologia 22: 79-84

30. Sartor G (1984) Prevalence of type 2 diabetes in Sweden. Acta Endocrinol 105 (Suppl 262): 27-29

31. Zimmet P, Taylor R and Whitehouse S (1982) The new World Health Organization diagnostic criteria for oral glucose tolerance: prevalence rates of impaired glucose tolerance and diabetes mellitus in various Pacific populations. Bull WHO 60 (2): 279-282

32. Zimmet P, Taft P, Guinea A, Guthrie W, Thoma K (1977) The high prevalence of diabetes mellitus on a Central Pacific Island. Diabetologia 13: 111-115

33. Haavisto M, Mattila K and Rajala S (1983) Blood glucose and diabetes mellitus in subjects aged 85 years or more. Acta Med Scand 214: $239-244$

34. Jarrett RJ (1984) Type 2 (non-insulin-dependent) diabetes mellitus and coronary heart disease - chicken, egg or neither. Diabetologia 26: $99-102$

35. Malins JM (1974) Glucose tolerance and the diabetic population. Postgrad Med 50: 529-537

36. Andres R (1971) Aging and diabetes. Med Clin North Am 55; $835-846$

37. DeFronzo R (1981) Glucose intolerance and aging. Diabetes Care 4: $493-501$

38. Chen M, Bergman RN, Pacini G, Porte D (1985) Pathogenesis of age-related glucose intolerance in man: insulin resistance and decreased B-cell function. J Clin Endocrinol Metab 60:13-20

39. Leblanc J, Nadeau A, Boulay M, Rousseau-Migneron S (1979) Effects of physical training and adipocity on glucose metabolism and 123 I-insulin binding. J Appl Physiol 46: 235-239

40. Dudl RJ, Ensinck JW (1977) Insulin and glucagon relationships during aging in man. Metabolism 26: 33 41

41. Cerasi E, Luft R (1972) Clinical diabetes and thesis of pathogenesis. In: Steiner D, Freinkel N (eds) Handbook of physiology, Section 7. Endocrine pancreas, Vol 1. American Physiological Society. Washington. DD pp 627-640

42. Zimmet P, Whitehouse S (1979) The effect of age on glucose tolerance: studies in a Micronesian population with a high prevalence of diabetes. Diabetes 28: 617-623

Received: 21 October 1985

and in revised form: 11 June 1986

Dr. Jaakko Tuomilehto

National Public Health Institute

Mannerheimintie 166

SF-00280 Helsinki

Finland 